\title{
REVIEW DESIGN STRUKTUR BETON BERTULANG TERHADAP STRUKTUR BAJA PADA STRUKTUR GEDUNG DIATAS TANAH LUNAK
}

\author{
Widya Apriani $^{1)}$, Hendri Rahmat ${ }^{2}$ \\ ${ }^{1,2}$ Program Studi Teknik Sipil, Fakultas Teknik, Universitas Lancang Kuning \\ Jl. Yos Sudarso km. 8 Rumbai, Pekanbaru, Telp. (0761) 52324 \\ Email:widyaapriani@unilak.ac.id ${ }^{1)}$,hendri@unilak.ac.id ${ }^{2)}$ \\ DOI: http://dx.doi.org/10.29103/tj.v10i1.254
}

(Received: September 2019 / Revised: January 2020 / Accepted: Maret 2020)

\begin{abstract}
Abstrak
Salah satu permasalahan paling utama dalam pengoptimalisasi desain struktur bangunan adalah pemilihan jenis material struktur dan pemilihan dimensi profil elemen struktur. Dalam desain struktur, perlu dilakukan analisis untuk meminimalisasi biaya yang dikeluarkan oleh pemilik bangunan.. Umumnya digunakan material beton bertulang sebagai bahan utama, namun pada penelitian ini akan dikaji material baja sebagai bahan utama dan dilakukan perbandingan terhadap kedua material tersebut. Hal ini sangat dibutuhkan dalam perencanaan untuk memperoleh pembiayaan yang paling optimal dan efisien dengan kekuatan struktur yang sama. Metode yang digunakan pada penelitian ini metode elemen hingga dengan bantuan program SAP 2000. Hasil penelitian yang diperoleh berupa dimensi profil baja dan beton yang telah sesuai dengan batas kekuatan dan stabilitas struktur serta biaya dari masing masing elemen struktur tersebut. Terdapat perbedaan biaya yang cukup signifikan antara struktur beton bertulang dan struktur baja. Hal ini disebabkan karena berat sendiri material material baja lebih berat dari beton serta harga satuan struktur baja lebih mahal dari struktur beton. Pada kajian ini harga baja pada elemen kolom terpaut $15.17 \%$ lebih mahal dari elemen beton bertulang. Sedangkan pada elemen balok terdapat selisih $62.16 \%$ lebih mahal struktur baja dibandingkan struktur beton.
\end{abstract}

Kata kunci: Struktur Baja, Review Design, Struktur Beton Bertulang, Struktur Gedung

\begin{abstract}
One of the most critical problems in optimizing building structure design is the selection of the type of structural material and the variety of the structural element profile dimensions. In planning the structure, the study is carried out to minimize costs incurred by the building owner. In general, reinforced concrete used as the primary material, but in this study, steel material will examine as the primary material, and a comparison of the two materials will conduct. The optimization design is a need in planning to obtain the most optimal and efficient financing with the same structural strength. The method used in this study is numerical with the help of the Sap 2000 first program. The results of the research in the form of dimensions of steel and concrete profiles and work costs refer to the unit price obtained from the construction of the building. The difference in the material used in the structural redesign also influences the very significant price difference. This problem is due to the weight of the concrete itself is more substantial than steel. So it will affect the landscape that can use effectively and efficiently. And finally, in this study, the price of steel in the column adrift is $15.17 \%$ higher than reinforced concrete elements. While in the beam element, there is a difference of $62.16 \%$ more expensive steel structure than concrete structures.
\end{abstract}

Keywords: Steel Structure, Design Review, Reinforced Concrete Structures 


\section{Latar Belakang}

Konstruksi bangunan gedung saat ini umumya masih menggunakan rangka beton bertulang. Gedung yang menggunakan rangka material yang lain seperti baja ataupun komposit baja-beton pun masih terbilang sedikit. Untuk Bangunan dengan klasifikasi bertingkat rendah (ketinggian sampai dengan empat lantai) dan sedang (ketinggian antara lima sampai delapan lantai), masih jarang menggunakan rangka baja sebagai material struktur utamanya (Indonesia, 2005), oleh karena itu dengan melihat begitu banyak kelebihan yang dimiliki struktur baja seharusnya dapat meningkatkan minat penggunaan Struktur rangka baja yang sekarang masih kurang diminati (Kadir et al., 2017).

Kuat tekan yang tinggi merupakan kekuatan atau kelebihan utama dari struktur beton bertulang. Selain itu harga yang relatif ekonomis dan biaya pemeliharaan yang kecil, namun begitu material ini memiliki volume dan berat yang besar, hal ini yang menjadi kelemahannya. Sedangkan Portal material baja dinilai masih bisa bersaing dengan portal beton. Hal ini dikarenakan material baja memiliki keunggulan dibanding dengan beton dalam beberapa parameter. Baja memiliki kekuatan tarik dan tekan yang tinggi dengan berat struktur yang lebih kecil dibanding beton, sehingga pondasi yang akan direncanakan juga kecil bebannya(Yovi Surya Futariani, 2017).

Dalam suatu perencanaan struktur dibutuhkan tingkat efisiensi yang tinggi, kinerja struktur yang baik dan biaya yang paling minimum. Salah satu bangunan bertingkat sedang, yaitu Gedung Fakultas Teknik Universitas Lancang Kuning, memiliki jumlah dua lantai dan dibangun dengan menggunakan struktur beton bertulang. Penambahan bangunan direncanakan menggunakan beton bertulang, namun akan dilakukan review design dengan menggunakan struktur rangka baja. Penggunaan kedua material tersebut sebagai perbandingan suatu bangunan konstruksi gedung sebenarnya telah diteliti oleh banyak pihak. Penggunaan struktur baja sebagai pengganti struktur beton bertulanguntuk kolom dan balok pada gedung tersebut jika didasarkan atas $\phi M n$ dan $\phi P n$. dengan dimensi yang sama dari desain struktur beton lebih mahal, namun, dengan adanya pembaharuan peraturan tentang baja, yaitu SNI 1729:2015 tentang spesifikasi untuk bangunan gedung baja struktural, menjadi alasan tersendiri untuk meneliti studi kasus ini.

Penggunaan material baja masih kurang diminati dibandingkan dengan beton bertulang dalam konstruksi suatu bangunan bertingkat rendah maupun bertingkat sedang, meskipun sifat material dan metode konstruksi baja lebih menguntungkan (Bakhtiar, 2018). Maka, diperlukan kajian untuk melakukan desain gedung bertingkat rendah yang menggunakan beton bertulang menjadi struktur rangka baja yang berada di atas tanah lunak (Apriani et al., 2019). Penelitian ini juga ingin mengetahui apakah dengan menggunakan struktur rangka baja dari segi kinerja dan biaya akan menjadi lebih baik daripada beton bertulang (Fauzan, 2016). Tujuan penelitian ini adalah untuk menentukan efektivitas dari segi kinerja dan biaya struktur beton bertulang dan struktur baja untuk digunakan dalam perencanaan bangunan gedung.

\section{Metode Penelitian}

Waktu pelaksanaan penelitian dilakukan selama 11 bulan dimulai dari Februari hingga November 2019. Penelitian diawali dengan melakukan analisis 
perbandingan model struktur menggunakan program elemen hingga (SAP 2000). Data penelitian yang digunakan meliputi Pemodelan deskripsi struktur dan Perencanaan struktur eksisting pada penelitian ini mengambil kasus gedung perkantoran. Struktur direncanakan berdasarkan kriteria berikut ini (Badan Standardisasi Nasional 1726-2012, 2012):

Sistem struktur : Sistem Rangka Pemikul Momen Menengah (SRPMM)

Jumlah tingkat : 2 lantai

Tinggi tingkat tipikal : $4 \mathrm{~m}$

Jenis Tanah : tanah lunak, (KDS D)

Wilayah : Pekanbaru

Untuk mengetahui peta desain spektra pada koordinat tersebut:

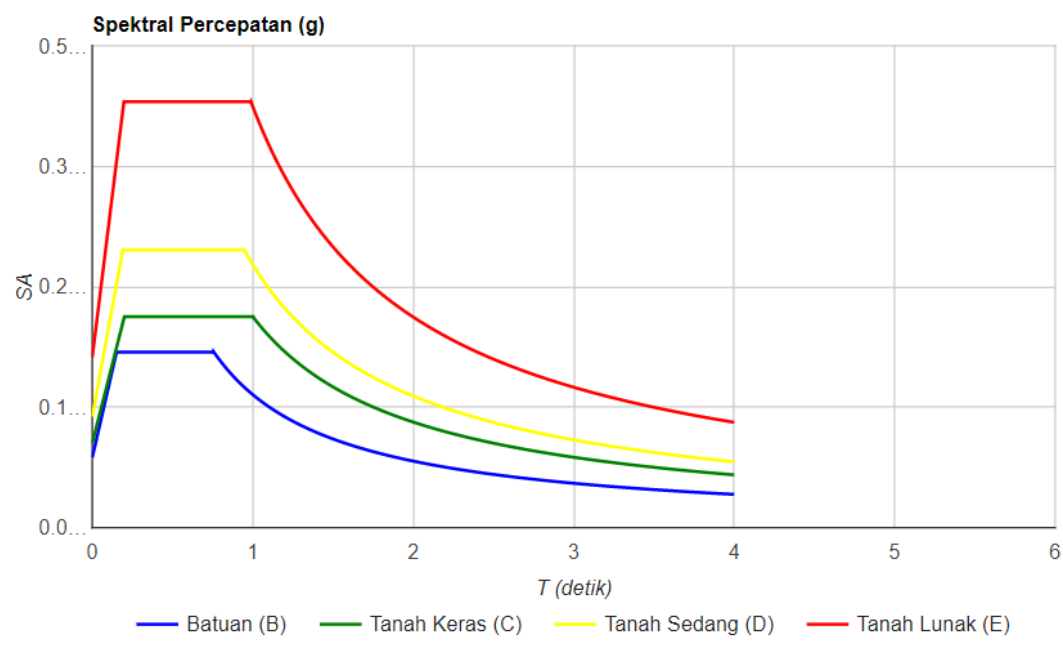

Gambar 1 Respons Spektra Rencana Pekanbaru (Badan Standardisasi Nasional 1726-2012, 2012)

Kuat tekan beton yang digunakan fc' $: 30 \mathrm{MPa}$

Baja tulangan :BJTD 39 (fy:390 MPa) dan BJTP 240 (fy $240 \mathrm{MPa}$ )

Modulus Elastisitas (E) baja tulangan: 2,1 x $105 \mathrm{MPa}$

berat jenis beton $\gamma \mathrm{t}$

: $25 \mathrm{kN} / \mathrm{m}^{3}$

Kategori Gedung

: Sekolah/kampus (Occupancy $=2)$

Bentuk bangunan :

Jumlah lantai

Tinggi lantai 1

$$
: 2
$$

Tinggi lantai 2-

$: 4 \mathrm{~m}$

Tinggi total bangunan

$: 3,5 \mathrm{~m}$

Luas Total

$: 7.5 \mathrm{~m}$

: $100 \mathrm{~m}^{2} @$ lantai

Data dimensi elemen bangunan dan struktur bangunan

Struktur Utama

Sistem Bangunan

Tipe dinding

Tebal pelat lantai
: Beton Bertulang

: Sistem SRPMM (Sistem Ragka Pemikul Momen Menengah)

: Bata

$: 12 \mathrm{~cm}$ 
Beban-beban rencana yang digunakan pada perhitungan struktur ini adalah sebagai berikut Beban Mati (DL), termasuk didalamnya berat sendiri struktur dan beban mati tambahan (SDL). Adapun perhitungan berat sendiri struktur secara otomatis dilakukan oleh program analisis struktur (SAP 2000) berdasarkan data massa jenis material yang disertakan dalam input program. Massa jenis material yang digunakan adalah sebagai berikut:

Beton bertulang $: 2.400 \mathrm{~kg} / \mathrm{m} 3$

Untuk Beban Mati Tambahan (SDL), besaran beban ini ditentukan berdasarkan data-data yang didapatkan dalam gambar arsitektural dan disesuaikan dengan peraturan pembebanan yang berlaku yaitu SNI 2847-2013(Badan Standardisasi Nasional, 2013a). Dengan demikian, beban mati tambahan yang digunakan untuk gedung ini adalah sebagai berikut:

Screed dan finishing lantai $\quad: 110 \mathrm{~kg} / \mathrm{m}^{2}$

Mekanikal, elektrikal, plumbing $\quad: 30 \mathrm{~kg} / \mathrm{m}^{2}$

Dinding bata

Anak tangga

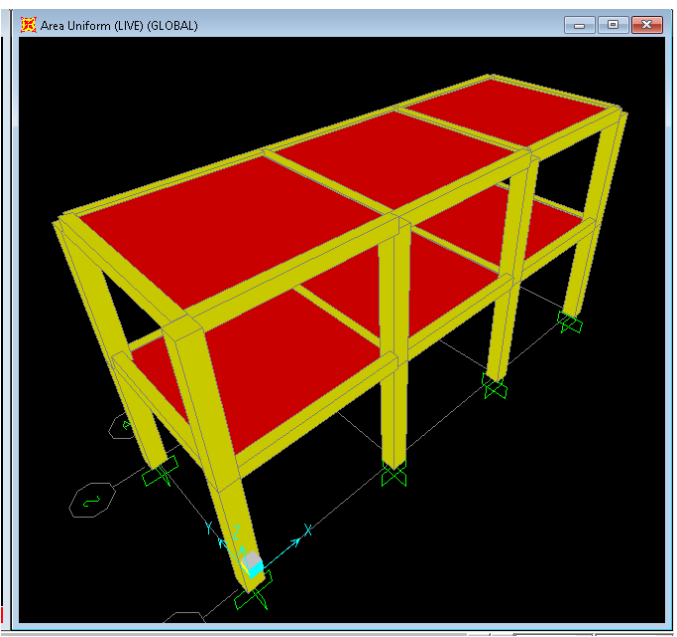

Gambar 2 3D Modelling Tampak Depan Gedung Kuliah

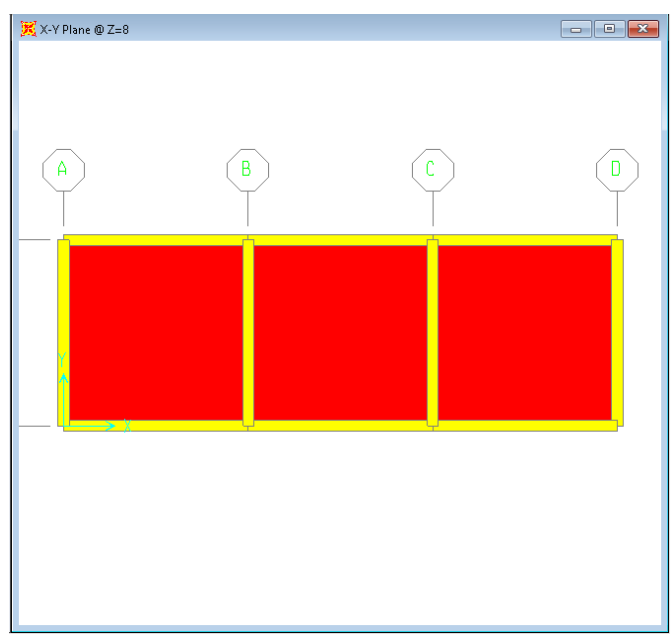

Gambar 3 Denah Balok Lt. Dasar (Tie Beam /Sloof)

Review Design Struktur Beton Bertulang Terhadap Struktur Baja Pada Struktur Gedung Diatas Tanah Lunak - Widya Apriani, Hendri Rahmat 
Beban Hidup (LL), Beban hidup ditentukan berdasarkan fungsi ruang pada masing-masing lantai yang besarannya ditentukan sesuai dengan peraturan pembebanan. Besaran beban hidup yang digunakan terdiri atas:

- LL Rumah Sakit (Ruang Pasien) : $200 \mathrm{~kg} / \mathrm{m}^{2}$

- LL Koridor $\quad: 400 \mathrm{~kg} / \mathrm{m}^{2}$

- LL Balkon / Teras $\quad: 300 \mathrm{~kg} / \mathrm{m}^{2}$

- LL Lantai atap $\quad: 100 \mathrm{~kg} / \mathrm{m}^{2}$

- LL Parkir $\quad: 200 \mathrm{~kg} / \mathrm{m}^{2}$

- LL Tangga dan bordes $\quad: 480 \mathrm{~kg} / \mathrm{m}^{2}$

Kombinasi pembebanan, Kombinasi Pembebanan Struktur Atas adalah sebagai berikut:

Kombinasi $1=1.4 \mathrm{DL}$

Kombinasi $1=1.2 \mathrm{DL}+1.6 \mathrm{LL}+0.5 \mathrm{Lr}$

Kombinasi $1=1.2 \mathrm{DL}+1.0 \mathrm{LL}+1.6 \mathrm{Lr}$

Kombinasi $4 \mathrm{a}=1.289 \mathrm{DL}+1.0 \mathrm{LL}+1.0 \mathrm{EX}+0.3 \mathrm{EY}$

Kombinasi $4 \mathrm{~b}=1.289 \mathrm{DL}+1.0 \mathrm{LL}+0.3 \mathrm{EX}+1.0 \mathrm{EY}$

Kombinasi $5 \mathrm{a} \quad=0.811 \mathrm{DL}+1.0 \mathrm{EX}+0.3 \mathrm{EY}$

Kombinasi $5 \mathrm{~b}=0.811 \mathrm{DL}+0.3 \mathrm{EX}+1.0 \mathrm{EY}$

Dengan memperhatikan DL adalah Beban Hidup, LL adalah beban mati, LL adalah beban hujan, EX adalah beban gempa arah X, dan EY adalah beban gempa arah Y.

Penelitian dimulai dengan melakukan pengumpulan data berupa data tanah, as built drawing, dan spesifikasi bahan bangunan dengan memperhatikan SNI pembebanan. Selanjutnya dilakukan analisis strukur dengan menggunakan program komputer untuk dilakukan perbandingan perhitungan struktur beton bertulang(Badan Standardisasi Nasional, 2013b) dan struktur baja(Segui, 2005). Komparasi terhadap biaya dan kinerja struktur menjadi batasan permasalahan yang diambil.

\section{Hasil dan Pembahasan}

Dari hasil perencanaan SAP 2000 dan perhitungan melalui Microsoft Excel, didapat pendekatan analisa hitungan Kolom:

Tabel 1 Hasil analisis balok beton bertulang

\begin{tabular}{|c|c|c|c|c|c|c|}
\hline \multirow{3}{*}{ No } & \multirow{3}{*}{$\begin{array}{c}\text { Tipe } \\
\text { Balok }\end{array}$} & \multirow{3}{*}{$\begin{array}{c}\text { Ukuran } \\
\text { Balok } \\
\text { (mm) }\end{array}$} & \multicolumn{3}{|c|}{ Pembesian } & $\begin{array}{c}\text { Momen } \\
(\mathrm{kNm})\end{array}$ \\
\hline & & & \multicolumn{2}{|c|}{ Tulangan } & \multirow[b]{2}{*}{ Sengkang } & \multirow[b]{2}{*}{$\mathrm{Mu}$} \\
\hline & & & Tumpuan & Lapangan & & \\
\hline 1 & B1 & $300 \times 250$ & 5D19 & 3D19 & D10-150 & 14.427 \\
\hline 2 & B2 & $400 \times 250$ & 5D19 & 3D19 & D10-150 & 17.734 \\
\hline
\end{tabular}


Tabel 2 Hasil analisis Kolom beton bertulang

\begin{tabular}{|c|c|c|c|c|c|}
\hline \multirow{3}{*}{$\begin{array}{c}\text { Ukuran } \\
\text { Kolom } \\
\text { (mm) }\end{array}$} & \multicolumn{5}{|c|}{ Pembesian } \\
\hline & \multicolumn{2}{|c|}{ Tulangan } & \multirow[t]{2}{*}{ Sengkang } & \multirow[t]{2}{*}{$\begin{array}{c}\text { Momen } \\
(\mathbf{k N m})\end{array}$} & \multirow[t]{2}{*}{$\mathbf{N u}(\mathbf{k N})$} \\
\hline & Tumpuan & Lapangan & & & \\
\hline $500 \times 500$ & $12 \mathrm{D} 22$ & D10-150 & D10-150 & 8.857 & 292.08 .00 \\
\hline
\end{tabular}

Tabel 3 Hasil perencanaan balok struktur baja (Setiawan, 2008)

\begin{tabular}{ll}
\hline Tipe Balok & B2 \\
\hline Profil Baja & WF300x270 \\
\hline $\mathrm{Mu}(\mathrm{kNm})$ & 11.47 \\
\hline $\mathrm{Mn}(\mathrm{kNm})$ & 46.742 \\
\hline$\phi \mathrm{M} \nu$ xN $\mu \varsigma$ & 41.668 \\
\hline $\mathrm{Vu}(\mathrm{kN})$ & 12.344 \\
\hline $\mathrm{Vn}(\mathrm{kN})$ & 55.475 \\
\hline$\phi \mathrm{Vn}(\mathrm{kN})$ & 62.527 \\
\hline
\end{tabular}

Tabel 4 Hasil perencanaan Kolom Struktur Baja (Setiawan, 2008)

\begin{tabular}{ll}
\hline Tipe Kolom & $\mathrm{K} 1$ \\
\hline Profil Baja & $400 \times 300 \times 13 \times 24$ \\
\hline$M u x(\mathrm{kNm})$ & 0.275 \\
\hline$M n x(\mathrm{kNm})$ & 142.199 \\
\hline$f M n x(\mathrm{kNm})$ & 157.998 \\
\hline$P u(\mathrm{kN})$ & 205.221 \\
\hline$P n(\mathrm{kN})$ & 311.37 \\
\hline$f P n$ & 345.96 \\
\hline
\end{tabular}
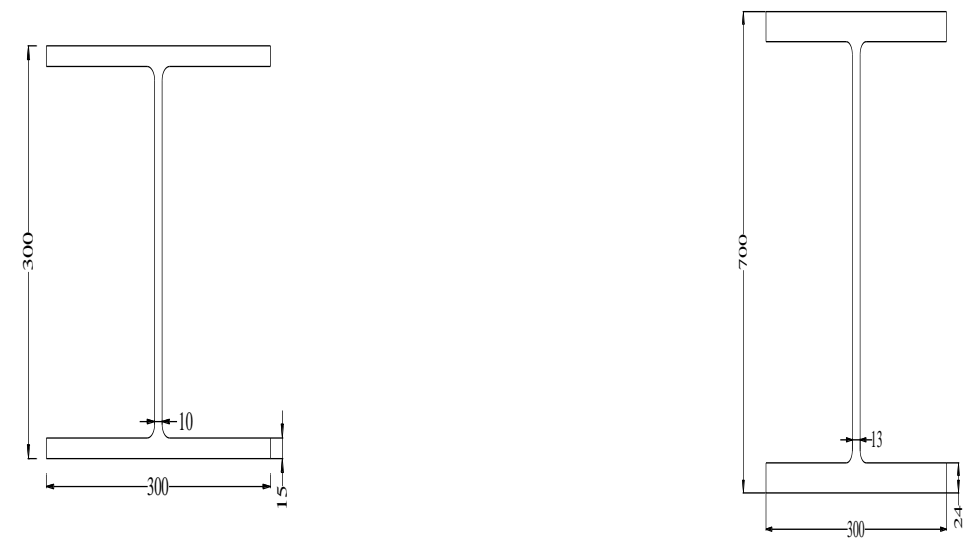

Gambar 4 Profil Baja hasil desain 
Concrete frame design berguna untuk memeriksa nilai dari gaya-gaya yang bekerja pada elemen struktur dan berfungsi sebagai parameter memeriksa apakah elemen-elemen yang kita desain sudah aman atau tidak (Badan Standardisasi Nasional, 2015). Jika ada yang berwarna merah, itu artinya tidak aman. Berdasarkan hasil analisis, semua batang berada pada possi yang aman. Hasil dari check ini diperlihatkan pada Gambar 5.

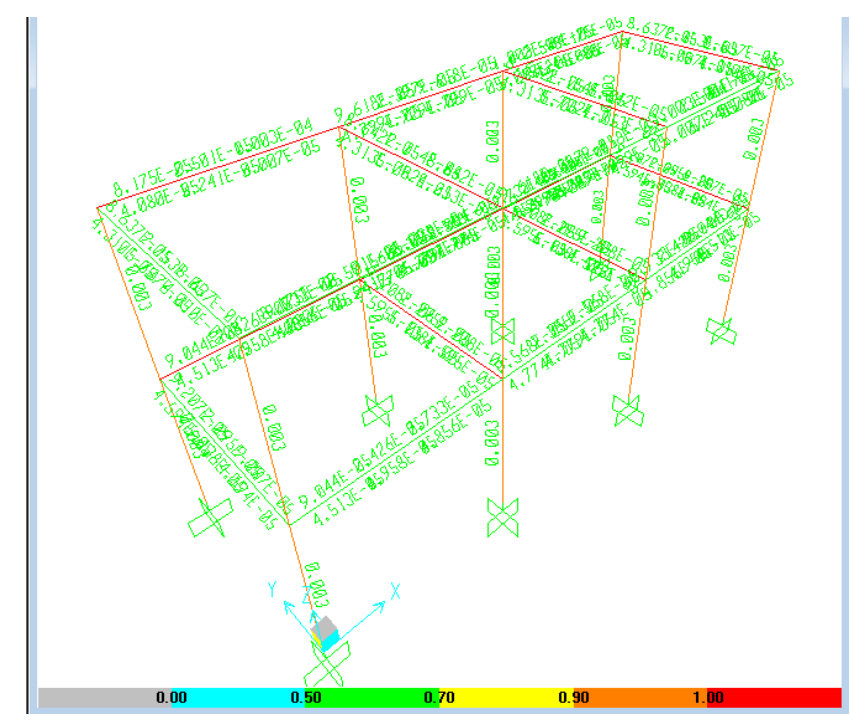

Gambar 5. Concrete Frame Design (Check of Structure )

Hasil pemeriksaaan kekuatan struktur enunjukkan dengan dimensi balok dan kolom yang terlah direncanakan tidak terjadi overstress sehingga dapat dikatakan aman. Sehingga analisis biaya bisa dilakukan terhadap kedua material tersebut. Harga beton bertulang diperoleh dari perkalian volume dan harga satuannya per $\mathrm{m}^{3}$.sedangkan pekeerjaan baja diperoleh dari harga per satu $\mathrm{kg}$ dikalikan dengan volume dalam satuan beratnya. Sehingga diperoleh persentase beda harga pada Tabel 5.

Tabel 5. Rancangan Anggaran Biaya pekerjaan beton bertulang dan Struktur Baja.

\begin{tabular}{|c|c|c|c|c|}
\hline NO. & PEKERJAAN & $\begin{array}{l}\text { VOLUME } \\
\text { SAT. }\end{array}$ & $\begin{array}{c}\text { HARGA } \\
\text { SATUAN } \\
\text { (Rp) }\end{array}$ & $\begin{array}{l}\text { TOTAL } \\
\quad(\mathbf{R p})\end{array}$ \\
\hline $\mathbf{A}$ & \multicolumn{4}{|c|}{ PEKERJAAN BETON BERTULANG } \\
\hline 1 & Pekerjaan Kolom & $16 \mathrm{~m}^{3}$ & $1,524,513.98$ & $24,392,223.62$ \\
\hline 2 & Pekerjaan Balok & $5.25 \mathrm{~m}^{3}$ & $1,524,513.98$ & $8,003,698.38$ \\
\hline \multicolumn{5}{|c|}{ Jumlah A= 32,395,921.99 } \\
\hline $\mathbf{B}$ & PEKERJAAN BAJA & & & \\
\hline $\mathbf{1}$ & $\begin{array}{l}\text { Memasang Tiang Baja } \\
\text { WF 400x300 (typ) }\end{array}$ & $528 \mathrm{~kg}$ & $54,459.80$ & $28,754,774.40$ \\
\hline
\end{tabular}




\section{$2 \quad$ Memasang Ring Beam WF200x 150 \\ $122.4 \mathrm{~kg} \quad 53,176.70$ \\ $6,508,828.08$ \\ (typ)}

Jumlah B $=35,263,602.48$

Dari Tabel 5 menunjukkan rancangan anggaran biaya komponen elemen balok dan kolom untuk struktur baja dan struktur beton bertulang. Volume elemen diperoleh dari hubungan jumlah elemen balok atau kolom dengan luas penampang balok dan kolom dan tinggi kolom. Untuk material baja volume diperoleh dengan mengailkan jumlah batang baja dengan berat satu batang baja dalam satuan kilogram. Selanjutnya dihitung harga satuan berdasarkan Analisa harga satuan yang diperoleh dari standar pekerjaan umum. Selanjutnya total harga diperoleh dari perkalian volume dan harga satuan.

Tabel 6 Beda harga antara Pekerjaan Kolom dan Balok

\begin{tabular}{cccc}
\hline \multirow{2}{*}{ NO. } & \multirow{2}{*}{ PEKERJAAN } & \multicolumn{2}{c}{ Beda Harga } \\
\cline { 3 - 4 } & & Rupiah & Persentase \\
\hline 1 & Pekerjaan Kolom & $4,362,550.78$ & $15.17 \%$ \\
\hline 2 & Pekerjaan Balok & $13,149,992.89$ & $62.16 \%$ \\
\hline
\end{tabular}

Tabel 6 menunjukkan selisih harga elemen balok dan kolom pada struktur baja dan struktur beton bertulang. Selisih harga diperoleh dari pengurangan harga elemen baja terhadap beton kemudian dibagi dengan harga baja dalam persentase. Berdasarkan perhitungan biaya tersebut, biaya pada struktur beton lebih murah dibandingkan dengan struktur baja dengan waktu pengerjaan dan masing masing material yang digunakan. Olehkarena itu struktur baja merupakan alternative kedua setelah beton. Pemilihan material struktur baja dapat dipertimbangkan jika meginginkan waktu pengerjaan yang lebih cepat. Namun jika jika tidak mempertimbangkan waktu sebagai factor utama maka pemilihan struktur beton bertulang lebih unggul digunakan. Hasil desain dari factor kekuatan, kedua material menunjukkan kemanan dan profil yang optimal dalam pemilihannya. Dan pada akhirnya pada kajian ini harga baja pada elemen kolom terpaut $15.17 \%$ lebih mahal dari elemen beton bertulang. Sedangkan pada elemen balok terdapat selisih $62.16 \%$ lebih mahal struktur baja dibandingkan struktur beton.

\section{Kesimpulan dan Saran}

\subsection{Kesimpulan}

Kesimpulan yang diperoleh dari kajian ini adalah Penggunaan struktur baja sebagai pengganti struktur beton bertulang untuk kolom dan balok pada gedung tersebut jika didasarkan pada kekuatan struktur yaitu $\phi \mathrm{Mn}$ dan $\phi \mathrm{Pn}$ menghasilkan penampang elemen kolom dan balok yang optimal.

Selain itu dari segi biaya struktur baja memiliki biaya lebih tinggi dibanding dengan struktur beton bertulang. Akhirnya pada kajian ini harga baja pada elemen kolom terpaut $15.17 \%$ lebih mahal dari elemen beton bertulang. Sedangkan pada elemen balok terdapat selisih $62.16 \%$ lebih mahal struktur baja dibandingkan struktur beton. 


\subsection{Saran}

Untuk efektifitas dan efisiensi pembangunan gedung yang serupa kondisinya dengan penelitian ini dapat disaran untuk dilakukan terlebih dahulu review design agar pembiayaannya menjadi tepat guna

\section{Ucapan Terima Kasih}

Ucapan terima kasih kepada Univesitas Lancang Kuning yang telah mendukung terlaksananya penelitian dalam dana hibah skim Penelitian Utama Anggaran Penelitian APBU tahun 2019.

\section{Daftar Kepustakaan}

Apriani, W. et al. (2019) 'Perilaku Struktur Jembatan Baja Pelengkung Berdasarkan Spektrum Gempa', Jurnal Saintis, 19(02), p. 71. doi: 10.25299/saintis.2019.vol19(02).3924.

Badan Standardisasi Nasional (2013a) 'Beban minimum untuk perancangan bangunan gedung dan struktur lain'.Jakarta

Badan Standardisasi Nasional (2013b) Perancangan Struktur Beton Bertulang SNI 2847-2013. 1st edn. Jakarta.

Badan Standardisasi Nasional (2015) 'Spesifikasi untuk bangunan gedung baja struktural'.Jakarta

Badan Standardisasi Nasional 1726-2012 (2012) Tata Cara Perencanaan Ketahanan Gempa untuk Struktur Bangunan Gedung dan Non Gedung 1726-2012. Jakarta.

Bakhtiar, A. (2018) 'Proyek Peningkatan Jalan Menggunakan Metode Earned Value', Teras Jurnal, 8(2), pp. 401-408.

Fauzan, M. (2016) 'Optimalisasi Rencana Anggaran Biaya dan Waktu Pelaksanaan dengan Preseden Diagram Method (PDM)', Teras Jurnal, 6(2), pp. 131-141.

Indonesia, P. R. (2005) Peraturan Pemerintah Republik Indonesia Nomor 36 Tahun 2005 Tentang Peraturan Pelaksanaan Undang-Undang Nomor 28 Tahun 2002 Tentang Bangunan Gedung. Jakarta.

Kadir, J. I. et al. (2017) 'Evaluasi Desain Struktur Gedung Training Centre II', Jurnal Karya Teknik Sipil, 6(1), pp. 428-437.

Segui, W. T. (2005) Aisc 2005.

Setiawan, A. (2008) Perencanaan Struktur Baja dengan Metode LRFD. 2nd edn. Jakarta.

Yovi Surya Futariani (2017) Kajian Struktur Baja sebagai Alternatif Review Design Struktur Beton Bertulang (Studi Kasus pada Gedung LPTK FT UNY). Universitas Negeri Yokyakarta. 